\title{
Clicking for calamari: toothed whales can echolocate squid Loligo pealeii
}

\author{
P. T. Madsen ${ }^{1,2, *}$, M. Wilson ${ }^{1}$, M. Johnson ${ }^{2}$, R. T. Hanlon ${ }^{3}$, A. Bocconcelli ${ }^{2}$, \\ N. Aguilar de Soto ${ }^{4}$, P. L. Tyack ${ }^{2}$ \\ ${ }^{1}$ Zoophysiology, Department of Biological Sciences, University of Aarhus, Building 1131, 8000 Aarhus C, Denmark \\ ${ }^{2}$ Woods Hole Oceanographic Institution, and ${ }^{3}$ Marine Biological Laboratory, Woods Hole, Massachusetts 02543, USA \\ ${ }^{4}$ La Laguna University Tenerife, Canary Islands, Spain
}

\begin{abstract}
Squid play an important role in biomass turnover in marine ecosystems and constitute a food source for $\sim 90 \%$ of all echolocating toothed whale species. Nonetheless, it has been hypothesized that the soft bodies of squid provide echoes too weak to be detected by toothed whale biosonars, and that only the few hard parts of the squid body may generate significant backscatter. We measured the acoustic backscatter from the common squid Loligo pealeii for signals similar to toothed whale echolocation clicks using an energy detector to mimic the mammalian auditory system. We show that the dorsal target strengths of $L$. pealeii with mantle lengths between 23 and $26 \mathrm{~cm}$ fall in the range from -38 to $-44 \mathrm{~dB}$, and that the pen, beak and lenses do not contribute significantly to the backscatter. Thus, the muscular mantle and fins of $L$. pealeii constitute a sufficient sonar target for individual biosonar detection by toothed whales at ranges between 25 and $325 \mathrm{~m}$, depending on squid size, noise levels, click source levels, and orientation of the ensonified squid. While epipelagic squid must be fast and muscular to catch prey and avoid visual predators, it is hypothesized that some deep-water squid may have adopted passive acoustic crypsis, with a body of low muscle mass and low metabolism that will render them less conspicuous to echolocating predators.
\end{abstract}

KEY WORDS: Squid $\cdot$ Predator $\cdot$ Prey $\cdot$ Echolocation $\cdot$ Toothed whale Target strength

Resale or republication not permitted without written consent of the publisher

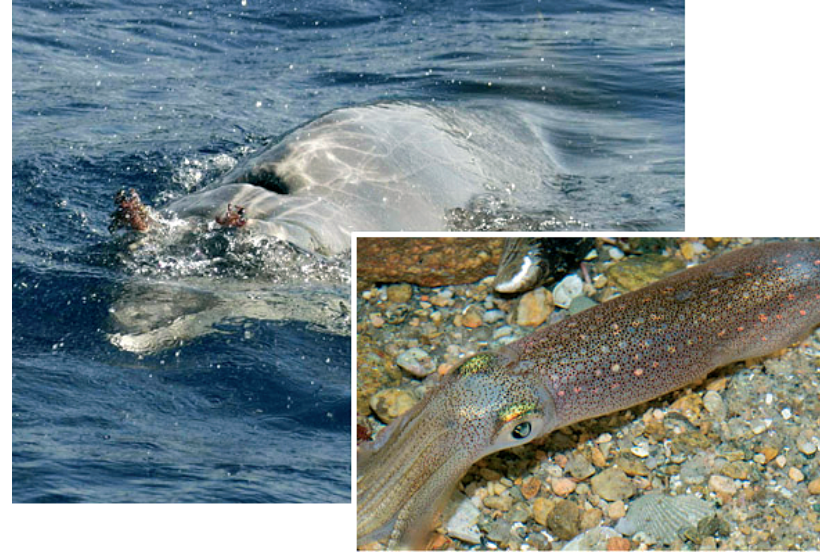

Toothed whales (e.g. Mesoplodon densirostris, top) may echolocate their squid prey (Loligo pealeii, bottom) at ranges of more than $100 \mathrm{~m}$

Photos: I. Dominguez (toothed whale) \& Roger Hanlon (squid)

\section{INTRODUCTION}

Echolocating toothed whales play an important role as top predators in marine ecosystems, where they target a range of prey taxa, including cephalopods (Clarke 1996). The annual marine biomass turnover by sperm whales alone has been compared to the total annual landings by the world's fishing fleets (Clarke 1977), and the combined top-down effects and evolutionary shaping forces of predation from echolocating toothed whales on prey within different trophic levels in the 
open ocean are therefore likely to be high (Katona \& Whitehead 1988, Bowen 1997). Cephalopods are a part of the diet in 60 out of 67 toothed whale species, and are the main prey of $40 \%$ of the toothed whale species primarily belonging to the deep-diving families of Globicephala, Ziphidae and Physeteroidae (Clarke 1996, Whitehead et al. 2003).

All toothed whale species carry homologous ultrasound-producing structures in their foreheads (Cranford et al. 1996), and recent data from free-ranging toothed whales provide strong evidence that they use echolocation as their primary sensory modality for finding and catching prey (Johnson et al. 2004, Miller et al. 2004, Akamatsu et al. 2005, Madsen et al. 2005a, Watwood et al. 2006). Sound is therefore a key parameter in the sensory interface between toothed whales and their prey, and should be considered when evaluating the behavioral ecology, sensory physiology, and life history strategies of the large number of marine organisms preyed upon by these echolocating predators.

However, Fristup \& Harbison (2002) observed that 'Squids are challenging targets for echolocation. Except for the chitinous beak, squid tissue has acoustic properties that are too similar to seawater to effectively reflect sound' (p. 44) and cite several authors for low target strength (TS) values of $-55 \mathrm{~dB}$ for squid. On that basis, they conclude that sperm whales most likely do not use echolocation for location and capture of squid, and they hypothesize that sperm whales may instead use vision for prey location and capture (Fristrup \& Harbison 2002). Thus, there is conflict between recent behavioral and acoustic data, strongly supporting the fact that echolocation is the primary means by which deep-diving toothed whales find their predominantly cephalopod prey, and the assertion by Fristrup \& Harbison (2002) that squid have TS too weak to allow for effective biosonar detection. Man-made echosounders are increasingly used to survey squid populations (Jefferts et al. 1987, Goss et al. 2001) and even their gelatinous egg capsule masses on the sea floor (Foote et al. 2006), and empirical measurements of TS in different squid species have been made using different ultrasonic echosounder pulse types (Arnaya et al. 1989a,b, Benoit-Bird \& Au 2001, Goss et al. 2001, Kang et al. 2005). It is therefore clear that squid are detectable by active sonar systems. However, these studies also testify that the derived TS depend heavily on the type of echosounder pulse used (Arnaya et al. 1988), and the orientation (Kang et al. 2005), behavior (Arnaya \& Sano 1990) and species of the ensonified squid, making it difficult to evaluate the detectability of squid by echolocating toothed whales from such data (Fig. 1).

In this study, we measured the TS of a muscular squid species Loligo pealeii using signals similar to echolocation clicks produced by 2 types of toothed whales, together with an energy-detecting receiver that mimicked the toothed whale auditory system. In so doing, we tested the 2 hypotheses of Fristrup \& Harbison (2002): (1) that squid have very low target strengths and so are unsuitable for echolocation by toothed whales, and (2) that hard parts in the squid body dominate the acoustic backscatter. Applying the sonar equation (Fig. 1), we estimated the detection range of $L$. pealeii by toothed whales and explored the implications for passive and active acoustic predatorprey interactions in marine ecosystems.

\section{MATERIALS AND METHODS}

Click properties, playback and recording. Two click types were used. The first simulated the echolocation click of a large delphinid such as Risso's dolphin (Au et al. 2004, Madsen et al. 2004), with a duration of ca. $60 \mu \mathrm{s}$, a centroid frequency of $52 \mathrm{kHz}$ and a $-10 \mathrm{~dB}$ bandwidth (BW) of $32 \mathrm{kHz}$ (Fig. 2a,b). The second simulated the frequency-modulated click of a mediumsized beaked whale (Zimmer et al. 2005, Johnson et al. 2006), with a duration of around $210 \mu \mathrm{s}$, a centroid frequency of $51 \mathrm{kHz}$ and a $-10 \mathrm{~dB}$ BW of $24 \mathrm{kHz}$ (Fig. 2c,d). The click waveforms, sampled at $500 \mathrm{kHz}$, were loaded into an Agilent 33220A arbitrary waveform generator and transmitted via a Reson 2116 broadband transducer in a monostatic sonar configuration. The estimated half power beam of $16^{\circ}$ was consistent with measurements in the tank. The returning echoes were recorded with the same transducer with a calibrated receiving sensitivity of $-177 \mathrm{~dB}$ re $1 \mathrm{~V} / 1 \mu \mathrm{Pa}$ and a calculated receiving directionality index of $20 \mathrm{~dB}$ at $50 \mathrm{kHz}$. The recorded echoes returning from the

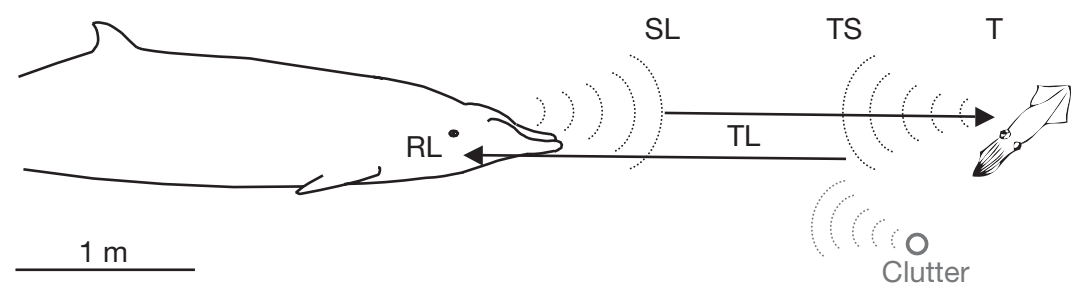

Fig. 1. Sonar parameters for an echolocating toothed whale and its cephalopod prey. The toothed whale generates a biosonar click with a source level (SL) that suffers from a 2-way transmission loss (TL) to the target (T). The target has a target strength (TS) equal to the ratio between the incident and reflected sound intensity. Detection of the received echo level (RL) at the auditory system of the whale can be masked by ambient noise or unwanted echoes (Clutter). A target is detected by the biosonar system if $\mathrm{RL}=\mathrm{SL}-2 \mathrm{TL}+\mathrm{TS}$ is sufficiently greater than the level of masking noise or clutter 

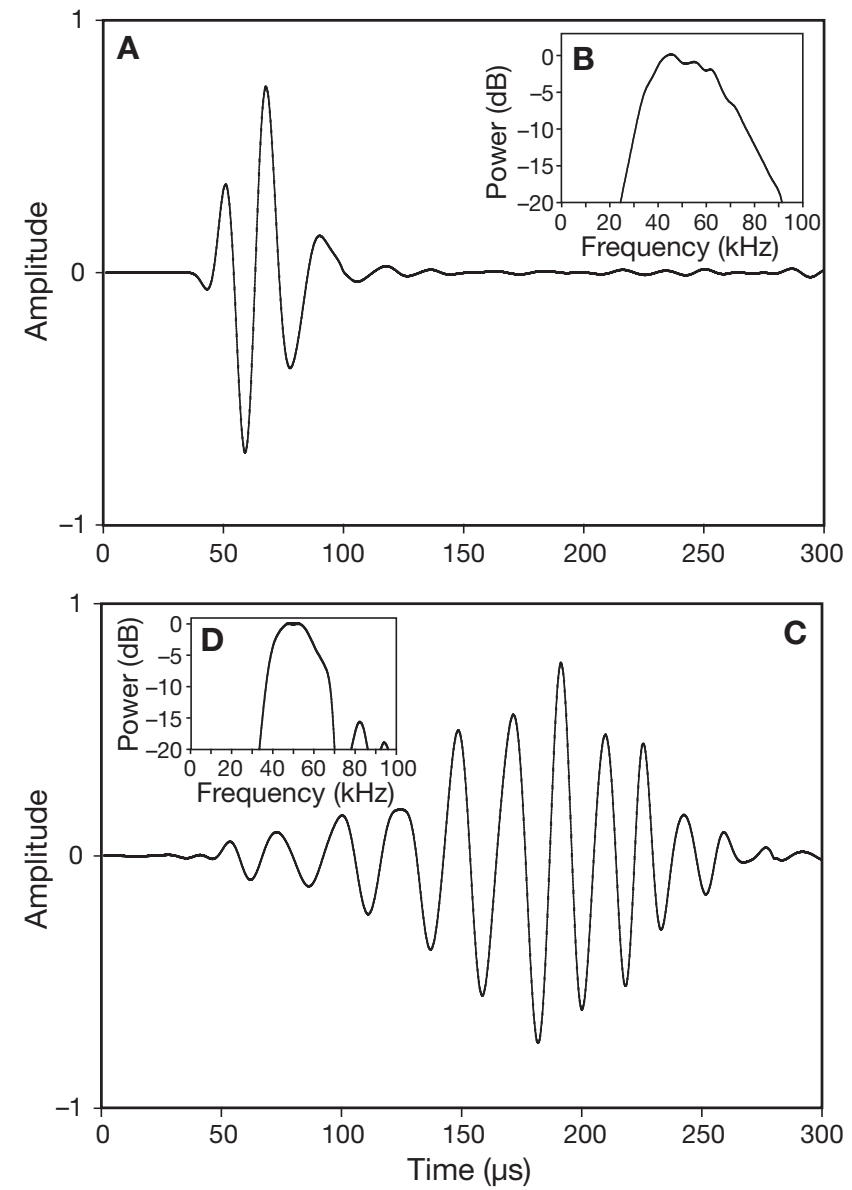

Fig. 2. (A) Waveform and (B) power spectrum of delphinid click. (C) Waveform and (D) power spectrum of beaked whale click. Both clicks were sampled at $500 \mathrm{kHz}$ and the fast Fourier transform (FFT) size is 256, giving a bin width of $3.9 \mathrm{kHz}$

target (Fig. 3) were amplified by $30 \mathrm{~dB}$ and band-pass filtered at 10 and $200 \mathrm{kHz}$ (2 poles) with a Reson VP2000 conditioning box, before digitization at $500 \mathrm{kHz}$ using a 12-bit Wavebook 512 (Iotech). All analyses were performed with custom scripts written in Matlab (Mathworks).

Tank, targets and sound field. Measurements were made in an oval tank $(4 \times 2 \times 1.5 \mathrm{~m}$ deep) filled with ocean-strength salt water at $18^{\circ} \mathrm{C}$. The transducer and target were placed at a depth of $75 \mathrm{~cm}$ and $2.9 \mathrm{~m}$ apart, a range in the theoretical Fraunhofer far-field region of both the transducer and the target within the frequency range 10 to $90 \mathrm{kHz}$. The target was aligned with the axis of the transducer by sight. The signal level in the far-field region of the transducer was measured using a calibrated B\&K 8103 hydrophone with a flat frequency response $( \pm 1 \mathrm{~dB})$ within the range of 10 to $90 \mathrm{kHz}$. The returning echo was range-gated and sampled at $800 \mathrm{kHz}$ for computer analysis using a Wavebook 512 12-bit analogue to digital converter.
Adult squid Loligo pealeii were caught off Cape Cod (Massachusetts, USA) and quickly transferred to large holding tanks at the Marine Resources Center at the Marine Biological Laboratory in Woods Hole (Massachusetts, USA). The squid showed normal swimming and chromatic behaviour (cf. Hanlon et al. 1999) and were fed live fish in the days between capture and the experiment. All experiments were performed on squid that had not been fed for at least $12 \mathrm{~h}$ to avoid addition of backscatter from stomach contents when deriving the TS of the squid. Ten squid with body lengths between 22 and $26 \mathrm{~cm}$ and body weights between 147 and $220 \mathrm{~g}$ (median $24 \mathrm{~cm}$ and $185 \mathrm{~g}$, respectively) were used for the experiment. Just prior to the experiment, the squid were gently transferred to a small holding tank where they were euthanized by adding a $3 \%$ volume of $70 \%$ ethanol to the seawater. The squid were immediately moved to the measurement tank while ensuring that no air bubbles, which could lead to overestimation of the TS, were caught in their body. Each squid in turn was suspended laterally on two $0.15 \mathrm{~mm}$
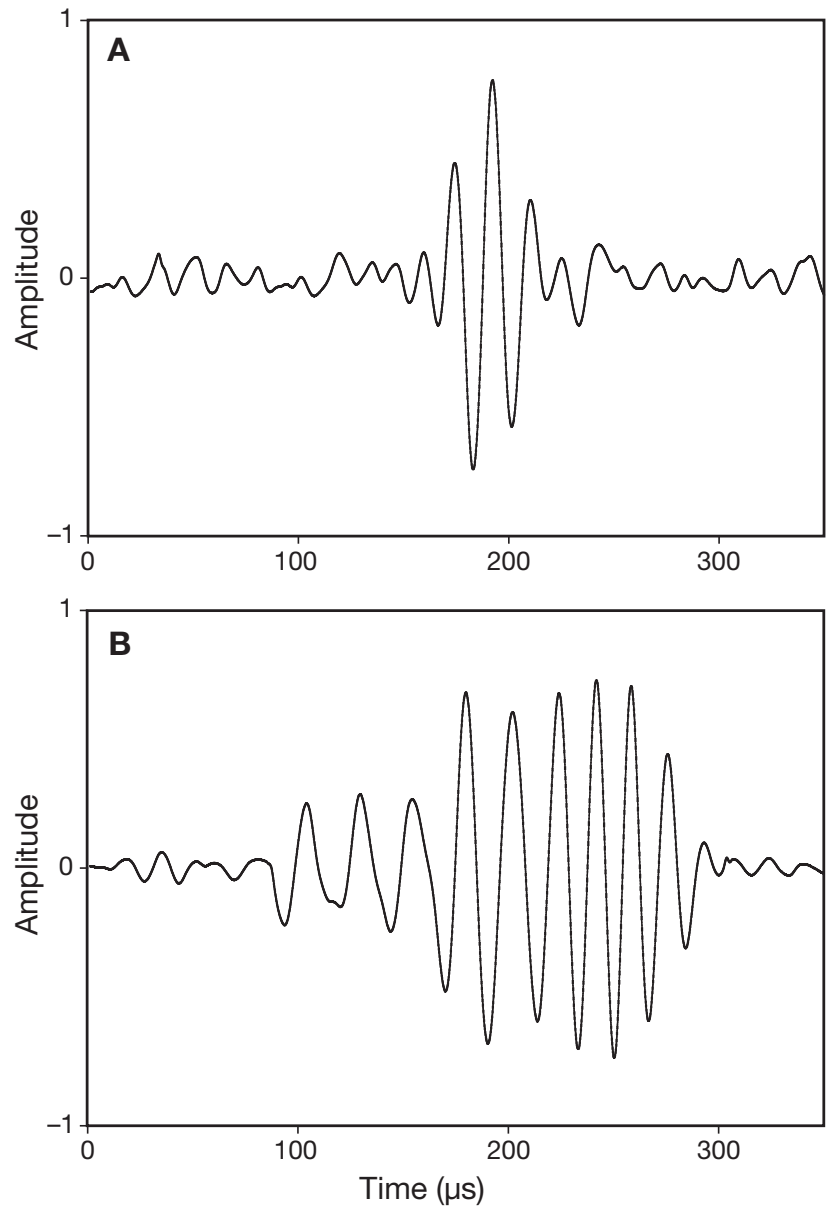

Fig. 3. Waveforms of echoes from an intact Loligo pealeii squid ensonified in a dorsal aspect using (A) a delphinid click, and (B) a beaked whale click 
monofilament lines adjusted so that the dorsal side of the target was perpendicular to the axis of the transducer with an error of less than $\pm 5^{\circ}$. All 10 squid were exposed to 50 clicks for each of the 2 click types and for each experimental condition.

Target strength measurements and calibration. TS is defined as the magnitude ratio between the incident intensity of the sound pulse impinging on the target and the intensity of the returning echo $1 \mathrm{~m}$ from the target on the same acoustic axis (Urick 1983):

$$
\mathrm{TS}=10 \log \left(\frac{I_{\mathrm{r}}}{I_{\mathrm{i}}}\right)
$$

where $I_{\mathrm{r}}$ is the intensity of echo return at $1 \mathrm{~m}$ and $I_{\mathrm{i}}$ is the incident intensity.

We estimated the peak to peak (pp) pressure target strength $\left(\mathrm{TS}_{\mathrm{pp}}\right)$ by subtracting the incident peak to peak sound pressure level (RL, dB re $1 \mu \mathrm{Pa}, \mathrm{pp})$ at the target from the returning peak to peak echo level (EL, $\mathrm{dB}$ re $1 \mu \mathrm{Pa}, \mathrm{pp})$, accounting for spherical propagation loss over the distance from target to receiver.

Toothed whale ears operate, like other mammalian auditory systems, as energy detectors integrating intensity over time up to a maximum frequencydependent duration $\tau$ (Green \& Swet 1966), the socalled integration time. Available data from auditory experiments with toothed whales show that they have very short integration times (around $264 \mu \mathrm{s}$ ) when detecting echolocation clicks (Au et al. 1988). Following $\mathrm{Au}$ (1993), we therefore computed the energybased target strength $\left(\mathrm{TS}_{\mathrm{E}}\right)$ as the ratio between the energy flux density of the incident click and the energy flux density of the returning echo with reference to $1 \mathrm{~m}$ from the target in a $264 \mu$ s window to give a more relevant measure for assessing the performance of toothed whale biosonar systems:

$$
\mathrm{TS}=10 \log \left(\frac{E_{\mathrm{r}}}{E_{\mathrm{i}}}\right)
$$

where $E_{\mathrm{r}}$ is the back-calculated energy of return at $1 \mathrm{~m}$ and $E_{\mathrm{i}}$ is the incident energy calculated as:

$$
\begin{aligned}
& E_{\mathrm{r}}=\int_{0}^{\tau} p^{2}(t) \mathrm{d} t \\
& E_{\mathrm{i}}=\int_{0}^{T} p^{2}(t) \mathrm{d} t
\end{aligned}
$$

where $p$ is the instantaneous pressure, the integration time $\tau$ is $264 \mu \mathrm{s}$, and $T$ is the duration of the incident click (in this case always $<264 \mu \mathrm{s}$ ).

The integration window of $264 \mu$ s was placed so as to cover the part of the echo that rendered the highest time integral value of the pressure squared (energy) for any given echo.

Prior to analysis, all the sampled waveforms were band-pass filtered (Butterworth, 8 poles) between 10 and $90 \mathrm{kHz}$. The experimental setup was calibrated before measuring each squid by placing a $5.08 \mathrm{~cm}$ steel sphere in the target position. The sphere has a theoretical TS of $-38 \mathrm{~dB}$, calculated from:

$$
\mathrm{TS}=10 \log \left(\frac{a^{2}}{4}\right)
$$

where $a$ is the radius of a spherical target in meters (Urick 1983).

$\mathrm{TS}_{\mathrm{pp}}$ and $\mathrm{TS}_{\mathrm{E}}$ were measured to be -38 and $-39 \mathrm{~dB}$, respectively and therefore in general agreement with the simple theoretical predictions (Urick 1983), and the derivation of the squid TS ought to have the same level of accuracy ( $\pm 1 \mathrm{~dB})$. In-band (10 to $90 \mathrm{kHz}$ ) tank reverberations limited squid TS measurements to $>-46 \mathrm{~dB}$ when using a minimum echo-to-noise ratio of $10 \mathrm{~dB}$ (in-band RMS sound pressure over the echo duration compared to the same length preceding interval). All statistics were performed in Matlab (Mathworks) on the linear scale values of the backscattering crosssection $\left(\sigma, \mathrm{m}^{2}\right)$ derived from the $\mathrm{TS}_{\mathrm{E}}$ for each squid, condition and click type (Urick 1983):

$$
\sigma=4 \pi \times 10\left(\mathrm{TS}_{\mathrm{E}} / 10\right)
$$

Thus, an idealized, perfectly reflecting sphere of $2 \mathrm{~m}$ radius has a TS of $0 \mathrm{~dB}$.

\section{RESULTS}

Each of the 10 squid was exposed to 50 pulses of each click type, and the mean backscattering crosssection of all 50 echoes was used to compute the target strength on a peak to peak ( $\mathrm{TS}_{\mathrm{pp}}$ ) and energy basis $\left(\mathrm{TS}_{\mathrm{E}}\right)$ (Fig. 4).

The median $\mathrm{TS}_{\mathrm{pp}}$ for the 10 intact squid using both click types was $-39 \mathrm{~dB}$. The median $\mathrm{TS}_{\mathrm{E}}$ was $-41 \mathrm{~dB}$, which was significantly lower than the $\mathrm{TS}_{\mathrm{pp}}$ for the same squid ( $p=0.002$, Wilcoxon rank sum test on the 10 individual backscattering cross-sections). This difference of a few $\mathrm{dB}$ between energy and peak intensity based TS derivations has also been found in other squid studies (Arnaya et al. 1988). Hereafter, we focus on the $\mathrm{TS}_{\mathrm{E}}$ due to its relevance for evaluating the detectability of squid by toothed whale biosonars. Fig. 4 shows all $\mathrm{TS}_{\mathrm{E}}$ measurements for the delphinid click (Fig. 4A) and the beaked whale click (Fig. 4B). There is no significant difference between the $\mathrm{TS}_{\mathrm{E}}$ derived with the delphinid click (median $-42.5 \mathrm{~dB}$ ) or with the beaked whale clicks (median -41.4 dB) $(\mathrm{p}=$ 0.85, Wilcoxon rank sum test).

To examine the contribution of hard parts to the overall TS, we surgically removed (1) the beak, (2) the eyes and (3) the pen while keeping the squid underwater during dissection. We alternated the 

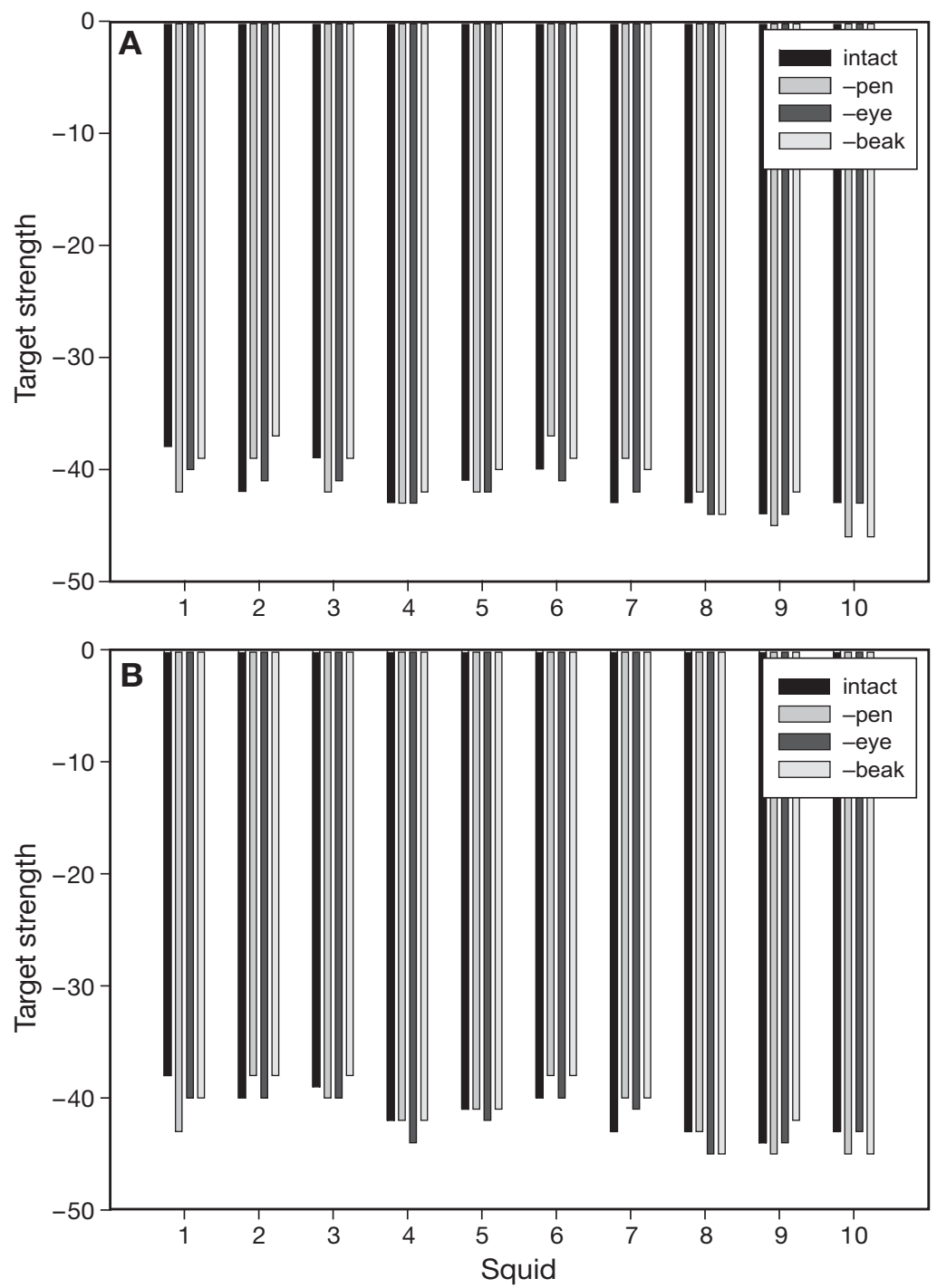

Fig. 4. Mean ( $=50$ clicks) energy-based target strength $\left(\mathrm{TS}_{\mathrm{E}}, \mathrm{dB}\right)$ measurements made with (A) the delphinid click, and (B) the beaked whale click. The order of removal of the pen, the eyes, and the beak was alternated between squid

order of body-part removal to account for potential biases in additive effects of TS reduction from removing body parts in the same order. All measurements were conducted within $60 \mathrm{~min}$ of euthanizing the squid; the cold water ensured that squid tissue remained fresh and translucent during this period. $\mathrm{TS}_{\mathrm{E}}$ values derived for the intact squid and after removal of the 3 body parts for both click types are shown in Fig. 4. To assess how body-part removal influenced TS, we computed the relative reduction in backscattering cross-section for each treatment for both click types and used a Wilcoxon signed rank test to test the null hypothesis that the paired differences before and after removal of a body part have a median of zero.
Removal of body parts did not result in a significant difference in scattering crosssection for either click type (delphinid click: eye, $\mathrm{p}=0.2$; pen, $\mathrm{p}=0.75$; beak, $\mathrm{p}=$ 0.68 ; beaked whale click: eye, $\mathrm{p}=0.18$; pen, $\mathrm{p}=0.75$; beak, $\mathrm{p}=0.29$ ). We also tested the hypothesis that the removal of all hard body parts would affect the backscatter, but found that the median reductions of -2.4 and $-1.4 \mathrm{~dB}$ of the initial normalized backscatter were not significant for either click type (delphinid: $\mathrm{p}=$ 0.43 ; beaked whale: $p=0.36$, Wilcoxon signed rank test). A larger sample size may likely have rendered these reductions significant, but it is safe to conclude that the hard parts do not dominate the acoustic backscatter. It is therefore concluded that the muscular mantle and fins of the squid are the dominant scatterers, and that the hard parts contribute little to the TS strength of this squid species, at least for frequencies representative of most teutophageous toothed whale clicks.

\section{DISCUSSION}

Echosounders are used routinely to survey for squid of commercial interest (Jefferts et al. 1987, Goss et al. 2001), but it has been debated whether toothed whales are able to detect squid (Fristrup \& Harbison 2002) using echolocation clicks of shorter duration and broader bandwidth (Au 1993, Madsen et al. 2004). We report the first TS measurements of a cephalopod using a toothed whale click and receiver model akin to that of the toothed whale auditory system. The derived dorsal-aspect TS of -38 to $-44 \mathrm{~dB}$ are slightly higher than, but comparable to, those measured from similar sized muscular squid species using the longer, pure tone pulses typical of echosounders (Arnaya et al. 1989a). When comparing squid with similar-sized fish species ensonified in the same frequency range, it is clear that the TS of squid are some 10 to $15 \mathrm{~dB}$ lower than those of fish species with swim bladders, such as gadoids, but are close to the TS of fish species without swim bladders, such as mackerels (Foote 1980, Jefferts et al. 1987).

Squid-eating toothed whale species produce a variety of echolocation clicks of durations from 20 to $300 \mu \mathrm{s}$ in the frequency range from 15 to $130 \mathrm{kHz}$ (Au 1993, Madsen et al. 2005b, Johnson et al. 2006). One hypothesis to account for the differences in duration of 
echolocation clicks is that species limited in peak power may compensate by producing longer clicks with a higher energy flux density for the same peak pressure (Au et al. 1999, Johnson et al. 2006). That, however, would only work if the echo return is matched by a similar increase in energy within the integration window. We used 2 click types representing the short echolocation clicks from large delphinids (Fig. 2A) and the longer frequency modulated clicks (Fig. 2B) from a beaked whale (Johnson et al. 2006) with no significant difference in the generated TS. Our finding that the $\mathrm{TS}_{\mathrm{E}}$ is the same for the 2 clicks shows, as expected, that a longer click duration and thereby an increase in energy content for the same peak sound pressure will give rise to a similar increase in the energy content of the returning echo, which is consistent with the energy hypothesis for longer echolocation clicks generated by some toothed whales.

A critical parameter for understanding interactions between echolocating predators and their prey, and for testing the Fristrup \& Harbison (2002) hypothesis that echolocation is not useful in hunting squid, is the range at which a toothed whale can detect its prey by echolocation. Little is known about the ranges at which toothed whales detect prey in the wild (Au et al. 2004, Madsen et al. 2004), but the extensive studies on trained delphinids in target detection experiments may offer a useful framework to estimate the range at which a squid of known TS can be detected. Au and coworkers have shown that a trained bottlenose dolphin can detect a $7.6 \mathrm{~cm}$ steel sphere at ranges of more than $100 \mathrm{~m}$ in noisy shallow water (Au 1993). Madsen et al. (2004) combined these data from trained delphinids with click parameters derived from wild false killer whales and Risso's dolphins to estimate the ranges at which different prey targets may be detected by foraging toothed whale predators. They estimated that free-ranging delphinids should be able to detect a $-50 \mathrm{~dB}$ target under low noise conditions out to ranges of $80 \mathrm{~m}$, and Au et al. (2004) used a similar approach to estimate that killer whales can echolocate salmon at ranges of more than $100 \mathrm{~m}$. More recently, Au et al. (2007) measured the TS from different fish species with porpoise and dolphin-like clicks and combined these values with data from echo detection experiments to estimate the ranges at which toothed whales can detect fish in different orientations with respect to the clicking whale. They found that a medium sized cod should be detectable at ranges out to 173 and $27 \mathrm{~m}$ for dolphins and porpoises, respectively.

Combining the median dorsal $\mathrm{TS}_{\mathrm{E}}$ value of $-41 \mathrm{~dB}$ measured from squid in this study with inferred detection thresholds of 33 and $48 \mathrm{~dB}$ re $1 \mu \mathrm{Pa}^{2} \mathrm{~s}$ at very low and high ambient noise levels (Au et al. 2007), respectively, we can estimate the ranges at which a toothed whale under noise-limited conditions (Fig. 1) will be able to detect an individual Loligo pealeii in a dorsal target aspect (Fig. 5). While beaked whales and large delphinids produce clicks with comparable energy flux source levels (Madsen et al. 2004, Zimmer et al. 2005, Au et al. 2007), they may hunt in quite different ambient noise environments. Thus, we consider the detection performance of a beaked whale in a low-noise deep ocean environment (Au et al. 2002) and that of a

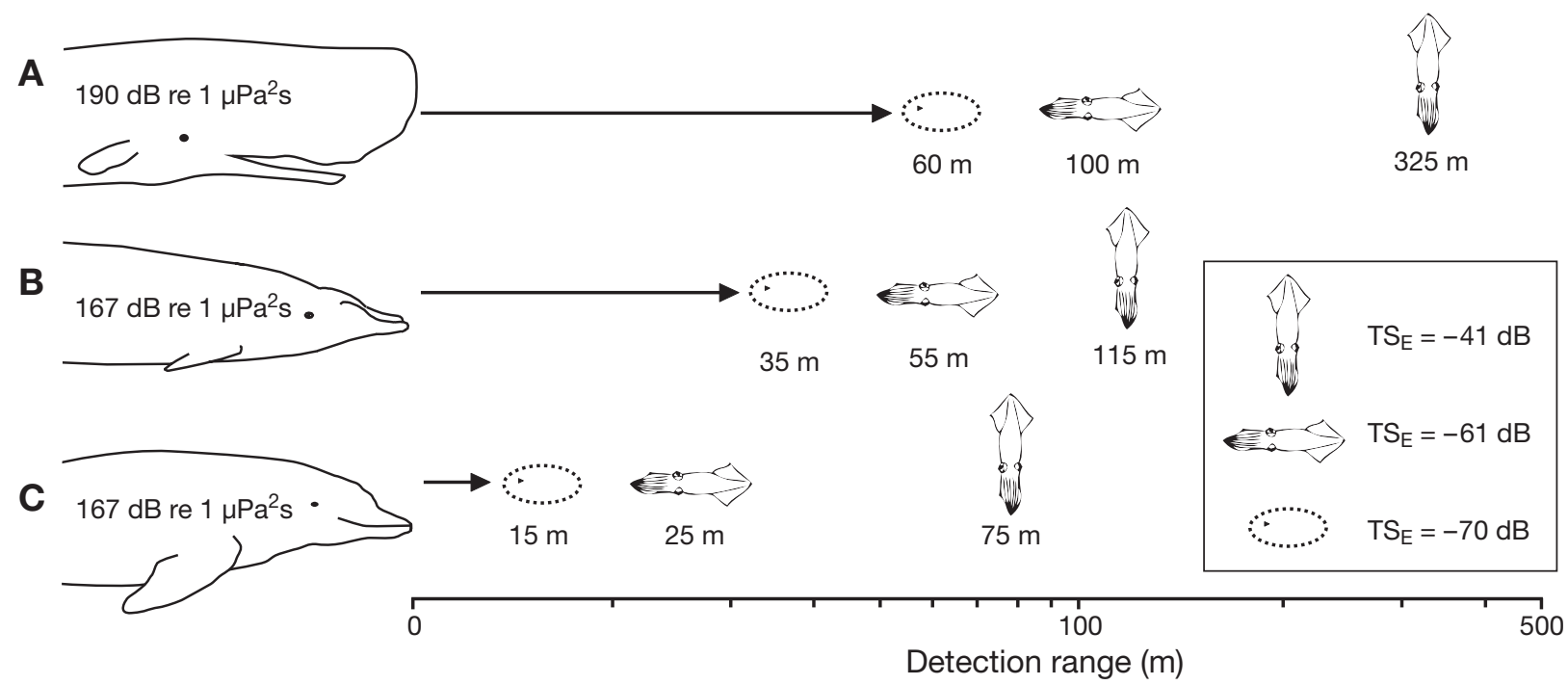

Fig. 5. Detection ranges (based on thresholds of Au et al. 2007) of 3 different targets with $\mathrm{TS}_{\mathrm{E}}$ of $-41,-61$ and $-70 \mathrm{~dB}$ by $3 \mathrm{differ}-$ ent toothed whale species: (A) a sperm whale with a sonar click source level of $190 \mathrm{~dB}$ re $1 \mu \mathrm{Pa}^{2} \mathrm{~s}$, and (B) a beaked whale and (C) a delphinid with sonar click source levels of $167 \mathrm{~dB}$ re $1 \mu \mathrm{Pa}^{2} \mathrm{~s}$. The estimated detection ranges for the beaked whale will also be applicable for the delphinid under low noise conditions and the estimated ranges for the delphinid will be applicable for the beaked whale under high noise conditions. Target with dotted line symbolizes a blimp-type cephalopod 
delphinid in relatively noisy shallow water (Au et al. 2007), but the detection range estimates are relevant for both individuals under either noise condition. As shown in Fig. 5, an echolocating toothed whale should be able to detect a $-41 \mathrm{~dB} \mathrm{TS}_{\mathrm{E}}$ target at a range of more than $100 \mathrm{~m}$ under low noise conditions, and under noisy conditions it should be able to detect the same target out to ranges of $\sim 75 \mathrm{~m}$.

The TS measured in a dorsal target aspect is the standard reported in fisheries acoustics (Foote 1980), and will most likely represent the highest TS of an elongated target (Au et al. 2007). The detection range of squid will therefore depend on the aspect at which it is ensonified, and so the detection ranges given above represent a maximum with respect to target orientation. Using pure tone echosounder pulses that tend to result in larger aspect-dependent changes than broadband pulses (Au et al. 2007), Arnaya et al. (1988) showed that the TS of a squid will drop by up to $20 \mathrm{~dB}$ when the squid is ensonified head-on compared to the dorsal aspect. If there is a corresponding reduction in $\mathrm{TS}_{\mathrm{E}}$, the detection range for a squid ensonified headon will drop to 55 and $25 \mathrm{~m}$ for the low and high noise conditions, respectively (Fig. 5).

The sperm whale generates the highest known sound levels in the animal kingdom, producing clicks with a source energy flux density of up to $193 \mathrm{~dB}$ re $1 \mathrm{\mu Pa}^{2} \mathrm{~s}$ (Møhl et al. 2003). Assuming the lowerfrequency sperm whale click gives rise to a similar TS of $-41 \mathrm{~dB}$ from an individual Loligo pealeii, and using a detection threshold of $48 \mathrm{~dB}$ re $1 \mathrm{\mu Pa}^{2} \mathrm{~s}$ ( $\mathrm{Au}$ et al. 2007), assuming a higher noise level in the deep sea at $15 \mathrm{kHz}$ compared to $50 \mathrm{kHz}$ (Urick 1983), we find that a sperm whale under noise-limiting conditions should be able to detect a $25 \mathrm{~cm} \mathrm{~L}$. pealeii at ranges between 100 and $325 \mathrm{~m}$ depending on target orientation (Fig. 5). Such long detection ranges result from the extremely high source levels and low absorption of the $15 \mathrm{kHz}$ sonar clicks produced by the hypertrophied nose of the sperm whale (Madsen et al. 2002, Møhl et al. 2003).

Thus, our modelling suggests that individual Loligo pealeii with mantle lengths around $25 \mathrm{~cm}$ likely are detectable by toothed whale biosonar at ranges between 25 and $325 \mathrm{~m}$ depending on squid orientation, click source levels and ambient noise and clutter levels (Figs. 1 \& 5). These detection ranges are broad estimates, but they are based on the first actual TS measurements of squid made with toothed whale clicks and an energy detector. If the ranges derived here are representative, a toothed whale biosonar system will significantly surpass the performance of other sensory systems such as vision or tactile senses in dark or murky waters. These results thus falsify the hypothesis by Fristrup \& Harbison (2002) that squid in general have TS too weak to be efficient sonar targets, and instead indicate that muscular $L$. pealeii provide toothed whale biosonars with longer prey detection ranges than the sensory systems of other teutophageous predators such as pinnipeds and fish.

Squid have adapted to a range of marine niches and have diversified tremendously in terms of metabolism, behaviour, body composition and life history (Hanlon \& Messenger 1996, Rosa et al. 2005, Seibel 2007). The body composition will thus vary significantly between different squid species from muscular, active squid to much less muscular, lethargic mid-water squid that use ammonia to stay neutrally buoyant (Clarke et al. 1985). Clearly, the backscattering properties of squid species with significantly different body compositions cannot be extrapolated from those of Loligo pealeii. However, the finding that the mantle, rather than the hard parts, dominates the backscatter from $L$. pealeii suggests that other larger muscular squids such as Illex sp. and Dosidicius sp. may have TS comparable to or greater than the L. pealeii measured here, and perhaps that the larger hard parts (cranium, beak, chitinous sucker rings, gladius) of these larger squid may also contribute to the acoustic backscatter. The large $(1.2 \mathrm{~m}$ and $50 \mathrm{~kg}$ ) and very muscular jumbo squid Dosidicus gigas in particular could have a TS of $-30 \mathrm{~dB}$ or higher, thus rendering it a strong target for toothed whales with long-range sonars, such as sperm whales (Madsen et al. 2002, Møhl et al. 2003), which have been reported to prey upon these large squid (Davis et al. 2007). Using a detection threshold of $48 \mathrm{~dB}$ re $1 \mu \mathrm{Pa}^{2} \mathrm{~S}$ as in Fig. 5, a sperm whale may be able to detect a jumbo squid with a $\mathrm{TS}_{\mathrm{E}}$ of $-30 \mathrm{~dB}$ at ranges of more than $1000 \mathrm{~m}$ under noise-limiting conditions. These long prey-detection ranges resulting from the large sound-generating nose may in part explain the successful ecologic radiation of sperm whales compared to other deep diving toothed whales (Madsen et al. 2002, Watwood et al. 2006).

While squid in the epipelagic and upper mesopelagic waters are muscular, fast predators with a high muscle mass and metabolic rate (Seibel 2007), the squid fauna in deeper water is dominated by neutrally buoyant, ammoniacal squid, such as members of Histioteuthidae and Cranchiidae (Voss 1967), with rather little muscle mass and a low metabolic rate (Seibel et al. 2004, Seibel 2007). These so-called blimps (due to their large volume, O'Dor 2002) are also targeted by echolocating toothed whales in large numbers (Clarke 1996), and given that the muscle mass of the mantle and the fins appears to be the dominant scatterer, the blimp species should have a considerably lower TS for the same mantle length when compared to Loligo pealeii, and thus be less detectable by toothed whale predators. Given the lack of TS measurements of these elusive creatures, we make a very conservative TS 
guess of $-70 \mathrm{~dB}$ for a small blimp with minute impedance differences between tissue and the surrounding water. Using this value, the noise-limited detection range for such a squid by a medium-sized toothed whale would be up to $25 \mathrm{~m}$ under very quiet detection conditions and $15 \mathrm{~m}$ in noisier conditions (Fig. 5). A sperm whale might be able to detect the same target at some $60 \mathrm{~m}$ under noise-limiting conditions. In either case, the likely low TS of ammoniacal squid will give rise to dramatically reduced detection ranges. However, even when using a hypothetical TS that is $15 \mathrm{~dB}$ lower than that cited by Fristrup \& Harbison (2002), deep sea squid appear to be acoustically detectable by echolocating toothed whales at ranges equivalent to many whale body lengths. The mesopelagic prey community often forms a dense patch or layer of organisms (Isaacs et al. 1974, Benoit-Bird et al. 2001, Madsen et al. 2005a), which in some cases will render biosonar detection of prey clutter-limited, rather than noiselimited (Fig. 1). However, schools of low TS prey may also constitute a larger target, allowing detection at longer ranges than for individual prey (Arnaya et al. 1989b, Madsen et al. 2002). L. pealeii do form large schools and will therefore be more detectable than the single squid measured here.

Studies on sensory interactions between squid and their predators have mainly focused on the capabilities of squid to implement visual crypsis with a highly adaptive camouflage system in their skin (Hanlon \& Messenger 1996, Hanlon \& Shashar 2003). Such a system will not work against echolocating toothed whales, but different body compositions with varying muscle mass and hard parts inevitably provide squid species with different capabilities to passively avoid biosonar detection or actively escape from capture attempts (Wilson et al. 2007). Squid with high muscle content will present a strong sonar target and a high potential energy return for an echolocating predator (Clarke et al. 1985), but the muscle will also potentially enable the squid to evade an approaching toothed whale (via jet escape), which in turn may invest more energy in pursuit and capture. On the other hand, squid with very little muscle mass constitute a less energetic meal and will be harder to detect acoustically (Fig. 5), but if detected they can do rather little to evade the predator (Seibel et al. 1997). Foraging toothed whales have been reported to adopt different tactics both within and across individuals in their pursuit of prey $(\mathrm{N}$. Aguilar de Soto et al. unpubl.) and these likely reflect the behaviour and tactics of the targeted prey. Thus, a whale may attempt to capture a few hard-earned energetic prey or many less-energetic prey that are easier to catch within a foraging dive (Madsen et al. 2005a, N. Aguilar de Soto et al. unpubl., V. Teloni et al. unpubl.). The passive acoustic properties of different body com- positions may thus form a component in the evolutionary driving forces acting on the functional morphology ecophysiology and life history of squid. While shallowwater squid must be fast and thus muscular to catch prey and avoid visual predators (O'Dor \& Webber 1991, Seibel 2007), some deep water squid may have opted for another strategy involving both visual (Hanlon \& Messenger 1996) and acoustic crypsis with a body of low muscle mass and low metabolism that will render them less conspicuous for biosonar-based predators.

We have demonstrated that the acoustic backscatter from some squid is strong enough to be detectable by echolocating toothed whales at long ranges. The evolutionary success of this means to locate prey is manifested by the massive ecologic radiation of teutophageous, deep diving toothed whales that exploit the large and basically unknown trophic levels of the deep sea inhabited by cephalopods. We predict that cuttlefish, a shallow water benthic cephalopod, will have just as high or higher TS as muscular squid due to the large air-filled cuttlebone, and we hope that future studies will elucidate how the acoustic interactions between echolocating toothed whales and their prey has played a role in shaping the life history, ontogeny, ecophysiological traits (Seibel et al. 1997) and behaviour (Hanlon \& Messenger 1996) of cephalopods since the Oligocene rise of toothed whale predators.

Acknowledgements. A. Lavery and T. Stanton kindly made the test tank available and offered many helpful suggestions for the experimental setup. S. Lindell, A. Shorter, A. Hansen and the MBL staff provided logistical support. W. Zimmer, K. Beedholm and B. K. Nielsen are thanked for helpful discussions on analysis and/or for comments on previous versions of the manuscript. This study was funded by the Oticon Foundation with additional support from Reson, and a Steno scholarship to P.T.M. from the Danish Natural Science Research Council. M.W. was funded by a PhD scholarship from the Faculty of Natural Sciences at Aarhus University and the PhD School SOAS. R.T.H. acknowledges partial funding from NOAA/NURP grant UAF-05-0133.

\section{LITERATURE CITED}

Akamatsu T, Wang D, Wang K, Naito Y (2005) Biosonar behaviour of free-ranging porpoises. Proc R Soc Lond B Biol Sci 272:797-801

Arnaya IN, Sano N (1990) Studies on acoustic target strength of squid. V. Effect of swimming on target strength of squid. Bull Fac Fish Hokkaido Univ 41:18-31

Arnaya IN, Noritatsu S, Iida K (1988) Studies on acoustic target strength of squid. I. Intensity and energy target strengths. Bull Fac Fish Hokkaido Univ 39:187-200

Arnaya IN, Sano N, Iida K (1989a) Studies on acoustic target strength of squid. III. Measurement of the mean target strength of small live squid. Bull Fac Fish Hokkaido Univ 40:100-115

Arnaya IN, Sano N, Iida K (1989b) Studies on acoustic target 
strength of squid. IV. Measurement of the mean target strength of relatively large-sized live squid. Bull Fac Fish Hokkaido Univ 40:169-181

$\mathrm{Au}$ WWL (1993) Sonar of dolphins. Springer Verlag, New York

$\mathrm{Au}$ WWL, Moore PW, Pawloski DA (1988) Detection of complex echoes in noise by an echolocating dolphin. J Acoust Soc Am 83:662-668

Au WWL, Kastelein RA, Rippe T, Schooneman NM (1999) Transmission beam pattern and echolocation signals of a harbor porpoise (Phocoena phocoena). J Acoust Soc Am 106:3699-3705

$\mathrm{Au}$ WWL, Lemonds DW, Vlachos S, Nachtigall PE, Roitblat HL (2002) Atlantic bottlenose dolphin hearing threshold for brief broadband signals. J Comp Pscyhol 116:151-157

$\mathrm{Au}$ WWL, Ford JK, Horne JK, Allman KAN (2004) Echolocation signals of free-ranging killer whales (Orcinus orca) and modelling of foraging for Chinook salmon (Oncorhyncus tshawytscha). J Acoust Soc Am 115:1-9

$\mathrm{Au}$ WWL, Benoit-Bird K, Kastelein R (2007) Modeling the detection range of fish by echolocating bottlenose dolphins and harbour porpoises. J Acoust Soc Am 121: 3954-3962

Benoit-Bird KJ, Au WWL (2001) Target strength measurements of Hawaiian mesopelagic boundary community animals. J Acoust Soc Am 110:812-819

Benoit-Bird KJ, Au WWL, Brainard RE, Lammers MO (2001) Diel horizontal migration of the Hawaiian mesopelagic boundary community observed acoustically. Mar Ecol Prog Ser 217:1-14

Bowen WD (1997) Role of marine mammals in aquatic ecosystems. Mar Ecol Prog Ser 158:267-274

Clarke MR (1977) Beaks, nets and numbers. Symp Zool Soc Lond 38:89-126

Clarke MR (1996) Cephalopods as prey. III. Cetaceans. Phil Trans R Soc Lond B Biol Sci 351:1053-1066

Clarke A, Clarke MR, Colmes LJ, Waters TD (1985) Calorific values and elemental analysis of eleven species of oceanic squid (Mollusca: Cephalopoda). J Mar Biol Assoc UK 65: 983-986

Cranford TW, Amundin M, Norris KS (1996) Functional morphology and homology in the odontocete nasal complex: implications for sound generation. J Morphol 228:223-285

Davis RW, Jaquet N, Gendron D, Markaida U, Bazzino D, Gilly W (2007) Diving behavior of sperm whales in relation to a major prey species, the jumbo squid, in the Gulf of California, Mexico. Mar Ecol Prog Ser 333:291-302

Foote KG (1980) Importance of the swimbladder in acoustic scattering by fish: a comparison of gadoid and mackerel target strengths. J Acoust Soc Am 67:2084-2089

Foote KG, Hanlon RT, Iiampietro PJ, Kvitek RG (2006) Acoustic detection and quantification of benthic egg beds of the squid Loligo opalescens in Monterey Bay, California. J Acoust Soc Am 119:844-853

Fristrup KM, Harbison GR (2002) How do sperm whales catch squids? Mar Mamm Sci 18:42-54

Goss C, Middleton D, Rodhouse P (2001) Investigations of squid stocks using acoustic survey methods. Fish Res 54:111-121

Green DM, Swets JA (1966) Signal detection theory and psychophysics. Peninsula Publishing, Los Altos, CA

Hanlon RT, Messenger JB (1996) Cephalopod behaviour. Cambridge University Press, Cambridge

Hanlon RT, Shashar N (2003) Aspects of the sensory ecology of cephalopods. In: Collin SP, Marshall NJ (eds) Sensory processing in the aquatic environment. Springer-Verlag, New York, p 266-282
Hanlon RT, Maxwell MR, Shashar N, Loew ER, Boyle KL (1999) An ethogram of body patterning behavior in the biomedically and commercially valuable squid Loligo pealei off Cape Cod, Massachusetts. Biol Bull 197:49-62

Isaacs JD, Tont SA, Wick GL (1974) Deep scattering layers: vertical migration as a tactic for finding food. Deep-Sea Res 21:651-656

Jefferts K, Burczynski J, Pearcy WG (1987) Acoustical assessment of squid (Loligo opalescens) off the central Oregon coast. Can J Fish Aquat Sci 44:1261-1267

Johnson MP, Madsen PT, Zimmer WMX, Aguilar de Soto N, Tyack PL (2004) Beaked whales echolocate on prey. Proc R Soc Lond B Biol Sci 271:S383-S386

Johnson MP, Madsen PT, Zimmer WMX, Aguilar de Soto N, Tyack PL (2006) Foraging Blainville's beaked whales (Mesoplodon densirostris) produce distinct click types matched to different phases of echolocation. J Exp Biol 209:5038-5050

Kang D, Mukai T, Iida K, Hwang D, Myoung JG (2005) The influence of tilt angle on the acoustic target strength of the Japanese common squid (Todarodes pacificus). ICES J Mar Sci 62:779-789

Katona S, Whitehead H (1988) Are Cetacea ecologically important? Oceanogr Mar Biol Annu Rev 26:553-568

Madsen PT, Wahlberg M, Møhl B (2002) Male sperm whale (Physeter macrocphalus) acoustics in a high-latitude habitat: implications for echolocation and communication. Behav Ecol Sociobiol 53:31-41

Madsen PT, Kerr I, Payne R (2004) Echolocation clicks of two free-ranging, oceanic delphinids with different food preferences: false killer whales Pseudorca crassidens and Risso's dolphins Grampus griseus. J Exp Biol 207: $1811-1823$

Madsen PT, Johnson M, Aguilar de Soto N, Zimmer WMX, Tyack PL (2005a) Biosonar performance of foraging beaked whales (Mesoplodon densirostris). J Exp Biol 208:181-194

Madsen PT, Carder DA, Beedholm K, Ridgway S (2005b) Porpoise clicks from a sperm whale nose: convergent evolution of toothed whale echolocation clicks? Bioacoustics 15:195-206

Miller PJO, Johnson MP, Tyack PL (2004) Sperm whale behaviour indicates the use of echolocation click buzzes 'creaks' in prey capture. Proc R Soc Lond B Biol Sci 271: 2239-2247

Møhl B, Wahlberg M, Madsen PT, Heerfordt A, Lund A (2003) The monopulsed nature of sperm whale clicks. J Acoust Soc Am 114:1143-1154

O'Dor R (2002) Telemetered cephalopod energetics: swimming, soaring, and blimping. Integr Comp Biol 42:1065-1070

O'Dor RK, Webber DM (1991) Invertebrate athletes: tradeoffs between transport efficiency and power density in cephalopod evolution. J Exp Biol 160:93-112

Rosa R, Pereira J, Nunes ML (2005) Biochemical composition of cephalopods with different life strategies, with special reference to a giant squid, Architeuthis sp. Mar Biol 146: 739-751

Seibel BA (2007) On the depth and scale of metabolic rate variation: scaling of oxygen consumption rates and enzymatic activity in the Class Cephalopoda (Mollusca). J Exp Biol 210:1-11

Seibel BA, Thuesen EV, Childress JJ, Gorodezky LA (1997) Decline in pelagic cephalopod metabolism with habitat depth reflects differences in locomotory efficiency. Biol Bull 192:262-278

Seibel BA, Goffredi SK, Thuesen EV, Childress JJ, Robison $\mathrm{BH}$ (2004) Ammonium content and buoyancy in mid-water 
cephalopods. J Exp Mar Biol Ecol 313:375-387

Urick RJ (1983) Principles of underwater sound. Peninsula Publishing, Los Altos, CA

Voss G (1967) The biology and bathymetric distribution of deep sea cephalopods. Stud Trop Oceanogr 5:511-535

Watwood SL, Miller PJO, Johnson M, Madsen PT, Tyack P (2006) Deep-diving foraging behavior of sperm whales (Physeter macrocephalus). J Anim Ecol 75:814-825

Whitehead H, MacLeod CD, Rodhouse P (2003) Differences

Editorial responsibility: Brent Stewart,

San Diego, California, USA in niche breadth among some teuthivorous mesopelagic marine predators. Mar Mamm Sci 19:400-406

Wilson M, Hanlon R, Tyack P, Madsen PT (2007) Intense ultrasonic clicks from echolocating toothed whales do not elicit anti-predator responses or debilitate the squid Loligo pealeii. Biol Lett 3:225-227

Zimmer WMX, Johnson MP, Madsen PT, Tyack PL (2005) Echolocation clicks of free-ranging Cuvier's beaked whales (Ziphius cavirostris). J Acoust Soc Am 117:3919-3927

Submitted: September 24, 2007; Accepted: October 19, 2007 Proofs received from author(s): November 14, 2007 